\title{
A NOÇÃO DE AGRICULTURA FAMILIAR NO DIREITO BRASILEIRO: UMA CONCEITUAÇÃO EM TORNO DE ELEMENTOS SOCIOECONÔMICOS E CULTURAIS
}

\author{
Felipe Franz Wienke*
}

\begin{abstract}
RESUMO
A lei 11.326/2006 positivou no direito brasileiro o conceito de agricultura familiar, identificado a partir de elementos essencialmente socioeconômicos. Contudo, ao estender seus efeitos ao conjunto de povos e comunidades tradicionais, a lei acabou por criar um segundo grupo de agricultores familiares, identificado a partir de elementos culturais. O objetivo do artigo é delimitar os contornos de ambos os grupos, apontando seus elementos centrais definidores.
\end{abstract}

PALAVRAS-CHAVES: agricultura familiar - povos e comunidades tradicionais justiça socioambiental

\begin{abstract}
The law 11.326/2006 included in Brazilian law the concept of family agriculture, identified from socioeconomic elements. However, extending its effects to the group of traditional peoples and communities, the law created a second group of family agriculture, identified from cultural elements. The objective of the article is to delimit the outlines of both groups, pointing out their defining central elements.
\end{abstract}

KEYWORDS: family agriculture - traditional peoples and communities - social and environmental justice

\footnotetext{
* Doutor em Direito pela Universidade Federal do Rio Grande do Sul.
} 


\section{INTRODUÇÃO}

As discussões em torno da problemática da agricultura familiar no Brasil ganham relevo a partir dos anos 80, quando emergem no país grupos sociais que passam a demandar políticas públicas voltadas para a pequena agricultura. A abordagem dominante nos anos 70/80, que previsualizava a extinção da pequena agricultura em prol da grande empresa rural, recebe alterações significativas, com a consolidação da agricultura familiar como categoria específica, o que lhe confere uma valoração positiva.

A partir dos anos 90, observa-se uma confluência de demandas em torno da problemática da reforma agrária e da agricultura familiar. Tais demandam geram políticas públicas direcionadas para estes grupos, sobretudo no âmbito do crédito rural. Em 1994, a criação do PRONAF torna-se um marco no financiamento da agricultura familiar, que até então se submetia as mesmas regras de crédito agrícola da grande produção rural.

Contudo, o direito brasileiro ainda carecia de uma delimitação jurídica sobre a noção de agricultura familiar. Tal déficit somente foi superado nos anos 2000, contexto no qual se observa uma produção legislativa que respondia aos anseios dos movimentos sociais rurais. A lei 11.326/2006, que definiu as diretrizes da Política Nacional da Agricultura Familiar, superou este vácuo legal, positivando o conceito de agricultura familiar para o direito brasileiro.

A noção trazida pela lei caracteriza-se pela sua complexidade, observando-se aspectos de identificação tanto socioeconômicos, como culturais. O objetivo do presente artigo é delimitar os contornos da noção de agricultura familiar no Brasil, investigando-se os diferentes elementos que o compõe. A hipótese aqui ventilada caminha em prol da construção de um conceito amplo, não limitado a itens socioeconômicos, mas abarcando um universo de aspectos culturais que podem ser resumidos em torno da ideia de povos e comunidades tradicionais.

Para tanto, o presente artigo é estruturado em dois capítulos. O primeiro é reservado para a análise daqueles elementos de origem socioeconômica, formadores do conceito aqui denominado de standard. O segundo capítulo é destinado à análise de uma noção 
definida a partir de elementos culturais, que claramente distingui-se da amplitude observada no primeiro grupo.

\section{A IDENTIFICAÇÃO DA AGRICULTURA FAMILIAR A PARTIR DE ELEMENTOS SOCIOECONÔMICOS: A DELIMITAÇÃO DO CONCEITO STANDARD}

Como dito, no cenário político-jurídico, a lei 11.326/2006 instituiu a Política Nacional de Agricultura Familiar. De acordo com o seu artigo $3^{\circ}$, considera-se agricultor familiar e empreendedor familiar rural aquele que pratica atividades no meio rural, atendendo simultaneamente aos seguintes requisitos: (a) não deter, a qualquer título, área maior de que quatro módulos fiscais; (b) utilizar predominantemente mão-de-obra da própria família nas atividades econômicas do seu estabelecimento ou empreendimento; (c) ter percentual mínimo de renda familiar originada de atividades econômicas de seu estabelecimento ou empreendimento; e (d) dirigir seu estabelecimento ou empreendimento com sua família.

Para uma melhor análise do conceito apresentado pela lei, torna-se pertinente revisitar isoladamente os quatro elementos referidos no artigo, quais sejam: módulo fiscal, mão-de-obra familiar; percentual mínimo de renda familiar; gerenciamento familiar do estabelecimento/empreendimento.

a) a noção de Módulo Fiscal: o conceito de módulo fiscal é utilizado no Brasil como parâmetro para a classificação dos imóveis rurais. Segundo a lei 8.629, de 25 de fevereiro de 1993, cujo teor regulamentou dispositivos constitucionais relativos à reforma agrária, o imóvel rural é todo prédio rústico de área contínua que se destine ou possa se destinar à exploração agrícola, pecuária, extrativa vegetal, florestal ou agro-industrial (artigo $4^{\circ}$, inciso I). Nos termos da lei, classifica-se como pequena propriedade o imóvel rural com área compreendida entre um e quatro módulos fiscais (artigo $4^{\circ}$, inciso II, alínea a); e média propriedade o imóvel rural com área compreendida entre quatro e quinze módulos rurais (inciso III, alínea b). Ainda que silencie a lei expressamente neste sentido, enquadra-se como grande propriedade o imóvel rural que ultrapasse o tamanho de 15 módulos fiscais. 
É importante salientar que o tamanho do módulo fiscal é variável regionalmente, de acordo com fatores que influenciam a capacidade de produção ${ }^{1}$. Tais fatores foram estabelecidos pela lei 4.504 , de 30 de novembro de 1964 (Estatuto da Terra), após as alterações introduzidas pela lei 6.746, de 10 de dezembro de 1979, quais sejam: (a) o tipo de exploração predominante em cada Município; (b) a renda obtida no tipo de exploração predominante; (c) eventualmente outras exploração existentes no Município que, embora não predominantes, sejam expressivas em função da renda ou da área utilizada e, finalmente; e (d) o próprio conceito de propriedade familiar ${ }^{2}$ definido pelo Estatuto da Terra (artigo 50, $\S 2^{\circ}$ ).

Nesta lógica, quanto maior o módulo fiscal, maior é a quantidade de terra necessária para sustentar uma família. Esta variação, portanto, mostra-se inversamente proporcional às condições de produtividade de uma região ${ }^{3}$. O módulo fiscal de cada Município, cujo tamanho varia no território nacional entre 5 e 110 hectares ${ }^{4}$, é definido pelo Instituto Nacional de Colonização e Reforma Agrária - INCRA, o que restou estabelecido através da Instrução Especial INCRA/N ${ }^{\circ} 20$, de 28 de maio de 1980 (com alterações posteriores). Em análise do mapa 1, é possível perceber

${ }^{1}$ Cabe salientar que as definições de módulo rural (apresentado anteriormente) e módulo fiscal não se confundem. Conforme salientado pelo site institucional do INCRA, o módulo rural é "calculado para cada imóvel rural em separado, e sua área reflete o tipo de exploração predominante no imóvel rural, segundo sua região de localização". O módulo fiscal, por sua vez, é estabelecido para cada município, e procura refletir a área mediana dos Módulos Rurais dos imóveis rurais do município (informações extraídas do site http://www.incra.gov.br/content/perguntasfrequentes-0. Acesso em 26/11/2015).

${ }^{2}$ Segundo o artigo $4^{\circ}$, inciso II, do Estatuto da Terra (lei 4504/64), a propriedade familiar é definida como todo o imóvel rural que, direta e pessoalmente explorado pelo agricultor e sua família, lhes absorva toda a força de trabalho, garantindo-lhes a subsistência e o progresso social e econômico, com área máxima fixada para cada região e tipo de exploração, e eventualmente trabalho com a ajuda de terceiros.

3 ARAUJO JUNIOR, Ari Francisco de; SHIKIDA, Claudio; ALVARENGA, Patrícia Silva. Economia política da disputa por terras em Minas Gerais. Revista de Economia e Sociologia Rural, Brasília, v. 46, n. 3, set. 2008, p. 811.

4 LANDAU, Elena Charlotte; CRUZ, Roberta Kelly da; HIRSCH, André; PIMENTA, Fernando Martins; GUIMARÃES, Daniel Pereira. Variação geográfica do tamanho dos módulos fiscais no Brasil. Documentos 146. Sete Lagoas: Embrapa Milho e Sorgo, 2012, p. 15. 
que os municípios que possuem módulos fiscais mais extensos localizam-se predominantemente na região norte do território nacional, enquanto que, de modo contrário, a região sul e sudeste concentra os municípios com menor módulo fiscal.

Em suma, o tamanho da propriedade é o primeiro critério estabelecido pela lei para a identificação do agricultor familiar. $\mathrm{O}$ critério, embora não uniforme, impõe uma relação entre agricultura familiar e pequena propriedade rural. Contudo, o agricultor familiar não se restringe ao proprietário da terra. $\mathrm{O}$ artigo $3^{\circ}$ da lei $11.326 / 2006$ utiliza o verbo deter, incluindo no rol de agricultores familiares não apenas os proprietários, mas também aqueles que possuem uma relação de posse com a terra. Neste sentido é o teor da Resolução 4.228, do Conselho Monetário Nacional - CMN, de 18 de junho de 2013, cujo teor regula os critérios e condições de concessão de crédito rural no âmbito do PRONAF. Segundo o teor do artigo $2^{\circ}$, são beneficiários do Programa os agricultores que "explorem parcela de terra na condição de proprietário, posseiro, arrendatário, comodatário, parceiro, concessionário do Programa Nacional de Reforma Agrária (PNRA), ou permissionário de áreas públicas”. 
ILUSTRAÇÃO 1 - Tamanho do módulo fiscal no território nacional

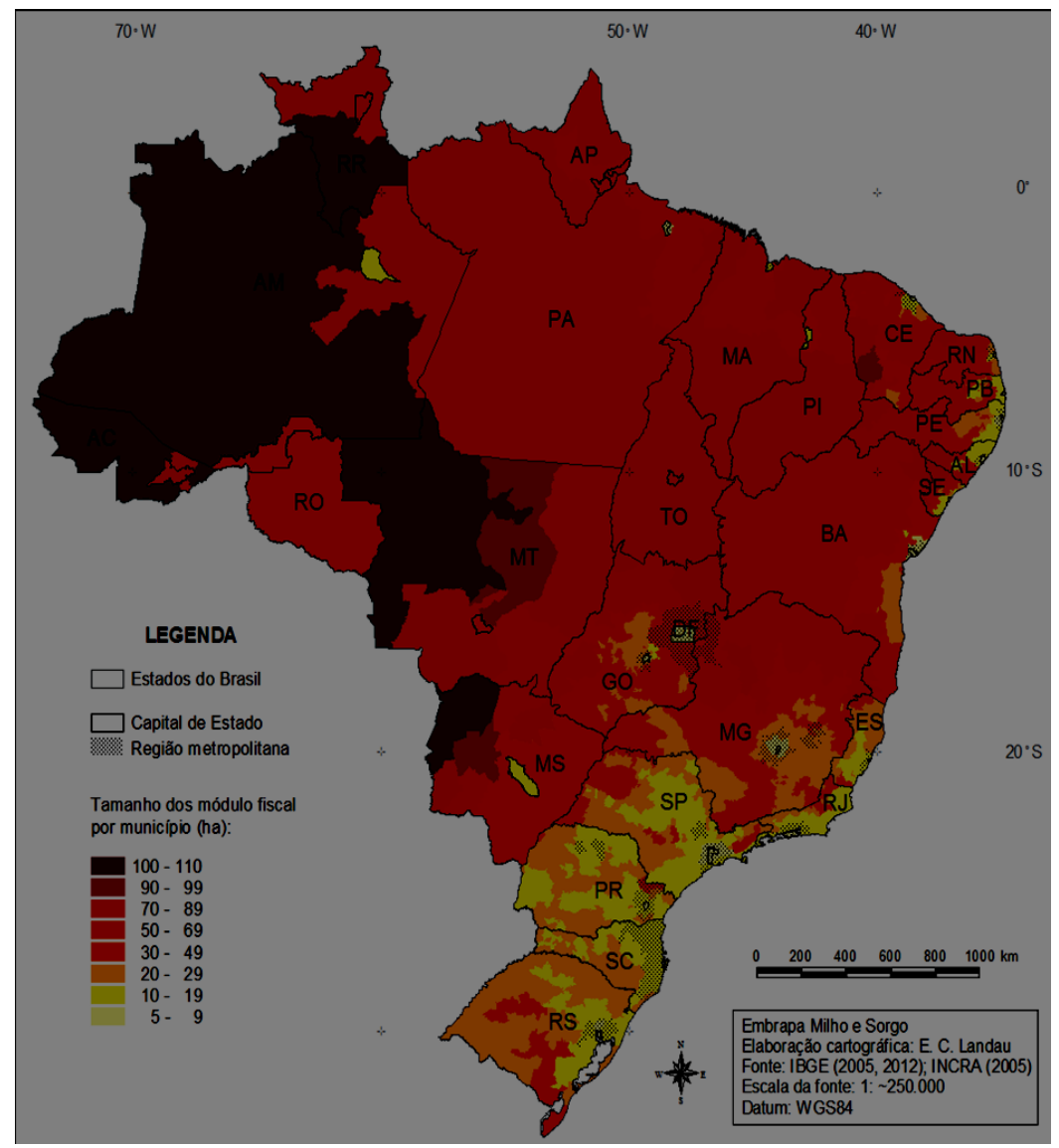

FONTE: EMBRAPA, 2012, p. 18.

b) A noção de mão-de-obra familiar: o conceito de mão-de-obra familiar ou de trabalho familiar não é encontrada diretamente na lei 11.326/2006. O texto legal utiliza apenas a expressão predominantemente mão-de-obra da própria família (artigo $3^{\circ}$, inciso II). O desafio, neste momento, é justamente precisar o que é mão-de-obra predominantemente familiar para o âmbito político administrativo brasileiro.

Embora o objetivo da lei seja justamente colocar em campos 
opostos a relação de trabalho familiar e o vínculo empregatício que tenha por base a legislação trabalhista, a lei não descarta a possibilidade de coexistência de ambos os modelos. Os regramentos do Ministério do Desenvolvimento Agrário - MDA sobre as políticas de apoio à agricultura familiar demonstram a coexistência das duas sistemáticas. É que se percebe, por exemplo, da análise dos critérios de concessão de crédito do Plano Safra da Agricultura Familiar 2014-2015 , definidos pelo Conselho Monetário Nacional, através do Manual de Crédito Rural - MCR (capítulo 10), conforme competência estabelecida pelo artigo $3^{\circ}$ da lei 11.326/06 (após redação dada pela lei 12.058/2009).

Assim, conforme a resolução 4.228, de 18 de junho de 2013, do Conselho Monetário Nacional, com vigência a partir de $1^{\circ}$ de julho de 2013, são beneficiários do Programa os agricultores e produtores rurais que "tenham o trabalho familiar como predominante na exploração do estabelecimento, utilizando mão de obra de terceiros de acordo com as exigências sazonais da atividade agropecuária, podendo manter empregados permanentes em número menor que o número de pessoas da família ocupadas com o empreendimento familiar" (MCR, capítulo 10, seção beneficiários 2 , artigo $1-\mathrm{e})^{6}$.

No âmbito do direito previdenciário percebe-se um cenário distinto. Nos termos da lei $n^{\circ} 8.213$, de 24 de julho de 1991, o regime de economia familiar é a atividade na qual "o trabalho dos membros da família é indispensável à própria subsistência e ao desenvolvimento socioeconômico do núcleo familiar e é exercido em condições de mútua dependência e colaboração, sem a utilização de

\footnotetext{
${ }^{5}$ O Plano Safra da Agricultura Familiar é um programa desenvolvido anualmente pelo MDA e pelo Conselho Nacional de Desenvolvimento Rural Sustentável, órgão colegiado deliberativo, regulamentado pelo Decreto 4.854, de 8 de outubro de 2003 , e que conta com a participação de representantes da sociedade civil e do governo federal. Através dos diferentes Planos Safras, desenvolvidos no âmbito do PRONAF (Programa Nacional de Fortalecimento da Agricultura Familiar), são celebrados contratos de crédito para a agricultura familiar.

${ }^{6}$ Nos termos da resolução anterior (Resolução 4.107, de 28 de junho de 2012) os beneficiários do Pronaf eram os agricultores e produtores rurais que tinham "o trabalho familiar como predominante na exploração do estabelecimento, utilizando apenas eventualmente o trabalho de terceiros, de acordo com as exigências sazonais da atividade agropecuária, podendo manter até 2 (dois) empregados permanentes".
} 
empregados permanentes" (art. $\left.11, \S 1^{\circ}\right)^{7}$.

Percebe-se, em suma, que não há uma definição específica para o conceito de trabalho familiar. Cada microssistema jurídico adota critérios próprios, sobretudo no que se refere à possibilidade e aos limites de coexistência da mão-de-obra familiar com o vínculo empregatício. Para os fins deste trabalho, que visa identificar um conceito legal de agricultura familiar, a utilização dos critérios do Programa Nacional de Agricultura Familiar parece mais adequada à realidade econômica e social vivenciada hodiernamente.

c) Os limites da composição de renda familiar: a renda familiar é o terceiro critério utilizado pela lei 11.326/06 para a identificação do agricultor familiar. Nos termos do artigo $3^{\circ}$, III, o agricultor familiar possui "percentual mínimo da renda familiar originada de atividades econômicas do seu estabelecimento ou empreendimento, na forma definida pelo Poder Executivo". A lei afasta a necessidade de que a renda familiar seja proveniente exclusivamente da atividade rural.

${ }^{7}$ Saliente-se que a jurisprudência do Supremo Tribunal de Justiça não flexibilizou esta exigência, conforme se denota da seguinte decisão:

PROCESSUAL CIVIL E PREVIDENCIÁRIO. AGRAVO REGIMENTAL NO AGRAVO DE INSTRUMENTO. APOSENTADORIA RURAL POR IDADE. REGIME DE ECONOMIA FAMILIAR. UTILIZAÇÃO DE ASSALARIADOS, CONFORME CONSTATADO PELA CORTE DE ORIGEM. BENEFÍCIO INDEVIDO. DESCARACTERIZAÇÃO DO REGIME PELA CORTE DE ORIGEM. REVERSÃO DO JULGADO. SÚMULA N. ${ }^{\circ}$ 7/STJ. DOCUMENTOS QUALIFICANDO O CÔNJUGE COMO TRABALHADOR RURAL. EXERCÍCIO POSTERIOR DE ATIVIDADE URBANA. INEXISTÊNCIA DE INÍCIO DE PROVA MATERIAL. AGRAVO DESPROVIDO.

1. Conforme estabelece o art. 11, inciso VII, $\S 1 .^{\circ}$, da Lei n. ${ }^{\circ} 8.213 / 91$, "Entende-se como regime de economia familiar a atividade em que o trabalho dos membros da família é indispensável à própria subsistência e ao desenvolvimento socioeconômico do núcleo familiar e é exercido em condições de mútua dependência e colaboração, sem a utilização de empregados permanentes." 2. Na hipótese em apreço, a Corte de origem assinalou que houve, no caso em tela, utilização de mão de obra assalariada na propriedade do cônjuge da Autora, descaracterizando, assim, o alegado labor rurícola em regime de economia familiar. 3. Desse modo, em observância ao que prescreve a norma acima citada, não há como acolher o pleito de concessão do benefício de aposentadoria rural por idade, sob alegação de exercício de atividade rurícola sob o regime de economia familiar. (...) 6. Agravo regimental desprovido. (Agravo Regimental no Agravo de Instrumento 1280513/SP. Relatora Ministra Laurita Vaz. Data do julgamento 20/04/2010) 
Para fins de concessão de crédito no âmbito do PRONAF, o Conselho Monetário Nacional, através da resolução 4.228/13 (artigo $2^{\circ}, d$ ), estabeleceu que o beneficiário deve apresentar no mínimo $50 \%$ (cinquenta por cento) da renda bruta familiar "originada da exploração agropecuária e não agropecuária do estabelecimento". A mesma resolução (artigo $2^{\circ}, f$ ) impõe que a renda bruta familiar do beneficiário da política de crédito, nos últimos 12 meses de produção normal, não ultrapasse $\mathrm{R} \$ 360.000,00$ (trezentos e sessenta mil reais), excluídos benefícios sociais e proventos previdenciários ${ }^{8}$.

A possibilidade de um percentual considerável da renda familiar ser provenientes de atividades não agrícolas atende às recentes transformações do meio rural. Conforme atenta Sérgio Scheneider, o contexto em que as pessoas não se ocupam exclusivamente com uma única atividade não constitui uma novidade histórica no campo e pode ser resumida no conceito de pluriatividade. O termo é utilizado para descrever o processo de diversificação do uso da força de trabalho que ocorre dentro e fora da propriedade. Em linhas gerais, pode-se definir a pluriatividade como,

um fenômeno através do qual membros das famílias que habitam no meio rural optam pelo exercício de diferentes atividades, ou, mais rigorosamente, pelo exercício de atividades não agrícolas, mantendo a moradia no campo e a ligação, inclusive produtiva, com a agricultura e a vida no espaço rural (SCHNEIDER, 2003, p. 112).

Nesta linha, pode-se afirmar que a pluriatividade constitui um elemento corrente na agricultura familiar, constituindo uma estratégia de diversificação produtiva e econômica. Ganham destaque aqui atividades como o turismo, bem como o desenvolvimento de mercados alternativos.

d) Direção do Estabelecimento Familiar: o quarto critério estabelecido pela Política Nacional de Agricultura Familiar diz respeito à direção do estabelecimento ou do empreendimento pela família. O ponto a ser investigado aqui guarda relação à amplitude da

${ }^{8}$ A resolução mencionada ampliou o limite anteriormente fixado pela resolução 4.107/12, a qual estabeleceu o teto de $\mathrm{R} \$ 160.000,00$ (cento e sessenta mil reais) para o enquadramento do agricultor na categoria de agricultor familiar. 
noção de família. A lei, bem como as resoluções do Banco Central regulamentadoras do Crédito Rural, silenciam neste aspecto. Os normativos referentes à emissão da Declaração de Aptidão ao Pronaf - DAP auxiliam neste desafio. O DAP, instituído pela Portaria $\mathrm{n}^{\mathrm{o}} 75$, de 17 de setembro de 2004, do Ministério do Desenvolvimento Agrário, é o instrumento que identifica os agricultores familiares (e/ou suas formas associativas organizadas em pessoas jurídicas) aptos a realizarem operações de crédito rural sob amparo do PRONAF (artigo $1^{\circ}$ ). Nos termos dos regramentos do Banco Central, a DAP é elaborada para as unidades de produções, prevalecendo "para todos os membros da família que compõem o estabelecimento rural e explorem as mesmas áreas de terra" (MCR, capítulo 10, seção 2, artigo 5).

A interpretação sistemática do Manual de Crédito Rural aponta para um conceito amplo de família, não adstrito aos graus de parentescos mais próximos. Esta é, aliás, o conceito obtido na página oficial do Ministério de Desenvolvimento Social, segundo o qual, unidade familiar, para fins de emissão das DAPs,

compreende o conjunto da família nuclear (marido ou companheiro, esposa ou companheira, e filhos) e eventuais agregados(as) que explorem o mesmo estabelecimento rural sob as mais variadas condições de posse, sob gestão estritamente da família, incluídos os casos em que o estabelecimento seja explorado por indivíduo sem família ${ }^{9}$.

Em linhas gerais, percebe-se que a noção de agricultura familiar a partir dos elementos socioeconômicos visa, em linhas gerais, se opor ao modelo agrícola convencional. Contudo, simplificações dualistas (agricultura de subsistência vs agricultura de excedentes, agricultura de baixa renda vs agricultura de grande lucratividade, agricultura artesanal vs agricultura moderna) devem ser evitadas. Como expõe o sociólogo Sérgio Schneider,

\footnotetext{
${ }^{9}$ Disponível em

http://www.mds.gov.br/segurancaalimentar/equipamentos/feirasemercados/arquivos/ declaracao-de-aptidao-ao-pronaf-dap.pdf. Acesso em 14/04/2015.
} 
Neste sentido, deve-se abandonar aquelas perspectivas de análise e interpretação que se baseiam em um raciocínio dualista, tipológico e ordenador da heterogeneidade social e econômica que caracteriza as formas familiares de produção. Para estas perspectivas, às formas familiares corresponderiam características como trabalho familiar, resistência à apropriação do excedente via mercado, propriedade de meios de produção, busca de autonomia etc. Já as formas capitalistas seriam definidas por assentarem-se em trabalho assalariado, apropriação de mais-valia, reprodução ampliada, racionalidade dirigida à obtenção de produtividade e rentabilidade, entre outros aspectos (SCHNEIDER, 2006, p. 4).

Distintamente desse grupo identificado por elementos socioeconômicos, percebe-se um segundo grupo de agricultores familiares, vislumbrado a partir de elementos culturais, ao qual a lei estende os benefícios decorrentes da lei 11.326. O estudo desse grupo é efetuado no capítulo seguinte.

\section{POVOS E COMUNIDADES TRADICIONAIS: A NOÇÃO DE AGRICULTURA FAMILIAR A PARTIR DE ELEMENTOS CULTURAIS}

O conceito standard de agricultura familiar adotado pela lei 11.326/2006, em interpretação conjunta com suas regulamentações administrativas, apresenta um conjunto de elementos estritamente socioeconômico. De fato, a emergência das preocupações políticas com a agricultura familiar nos anos 90 teve por foco o aumento da produtividade agrícola e a melhoria das condições sociais deste grupo, o que se consolidou na noção jurídica adotada em 2006.

A lei, contudo, ampliou este conceito, aportando elementos também culturais para qualificação do agricultor familiar. $\mathrm{O}$ artigo $3^{\circ}, \S 2^{\circ}$ inclui no rol de beneficiários da lei, um conjunto de comunidades tradicionais que não cumprem necessariamente os requisitos exigidos no conceito standard. Destaca-se neste rol,

- Sivicultores que cultivem florestas nativas ou exóticas e que promovam o manejo sustentável daqueles ambientes (inciso I);

- Aquicultores que explorem reservatórios hídricos com superfície total de até dez hectares ou ocupem quinhentos metros cúbicos de 
água, quando a exploração se efetivar em tanques-redes (inciso II);

- Extrativistas que exerçam sua atividade artesanalmente no meio rural, excluídos os garimpeiros e faiscadores (inciso III). Neste caso, a exigência acerca do tamanho da propriedade é dispensada;

- Pescadores que exerçam a atividade pesqueira artesanalmente (inciso IV);

- Povos indígenas que atendam os requisitos referentes à natureza da mão-de-obra, ao percentual mínimo de renda familiar e à direção familiar da produção (inciso $\mathrm{V}$ );

- Integrantes de comunidades remanescentes de quilombos rurais e demais povos e comunidades tradicionais (que atendam também os requisitos referentes à natureza da mão-deobra, ao percentual mínimo de renda familiar e à direção familiar da produção) (inciso VI).

Para o caso das comunidades extrativistas, dos povos indígenas e dos demais povos e comunidades tradicionais, o elemento "tamanho da propriedade" restou dispensada pela lei. Tal situação é justificada pela tradicional extensão das terras destes grupos, que não se enquadra no limite de quatro módulos fiscais estabelecidos para o conceito standard. É esta dispensa que possibilita o enquadramento dos povos e comunidades tradicionais no conceito legal de agricultura familiar.

Ao estabelecer a inclusão dos grupos acima mencionados como beneficiários da lei 11.326/2006, em termos práticos, a lei equipara estas comunidades aos demais agricultores familiares, criando um segundo grupo identificado a partir dos elementos nucleares da noção de comunidades tradicionais, notadamente elementos histórico-culturais. O grande desafio reside justamente na delimitação da noção de comunidades tradicionais. Observa-se na literatura internacional a utilização de diversas denominações para a categoria em foco, tais como autóctones, nativos, aborígenas e indígenas. Como destaca Isaias Montanari Junior, a expressão indígena, comumente observada em documentos internacionais, é ampla e abrange povos espalhados em todo o mundo. "Em comum, tem o fato de que cada um se identifica com uma comunidade própria, diferente acima de tudo da cultura do colonizador" (MONTANARI JUNIOR, 2013, p. 24).

Manuela Carneiro da Cunha e Mauro Almeida salientam a 
dificuldade de identificar os elementos caracterizadores do conceito. Como alertam os autores,

definir as populações tradicionais pela adesão à tradição seria contraditório com os conhecimentos antropológicos atuais. Definilas como populações que tem baixo impacto sobre o ambiente, para depois afirmar que são ecologicamente sustentáveis, seria mera tautologia. Se as definirmos como populações que estão fora da esfera de mercado, será difícil encontrá-las hoje (CUNHA, ALMEIDA).

Deste modo, os autores propõem uma metodologia enumerativa. "Por enquanto, achamos melhor definir as populações tradicionais de maneira extensional, isto é, enumerando seus membros atuais, ou os candidatos a membros" (Ibid). Lucila Pinsard Vianna salienta que o conceito de comunidades tradicionais que emerge nos anos 80 no Brasil mostra-se relativamente vago e genérico, mas não totalmente desprovido de interesses.

Sua disseminação responde a demandas tanto dos conservacionistas, das mais diversas linhas, quanto dos movimentos sociais rurais e, mais tarde, do socioambientalismo. Como categoria antropológica, essas populações podem se situar entre as chamadas sociedades rústicas. No meio ambientalista, populações tradicionais evoca os consagrados conceitos de sociedades tradicionais e sociedades complexas, adquirindo matiz utilitária, e, assim como no movimento social, passou a ter conotação política e ideológica (VIANNA, 2008, p. 207).

Segundo o relatório organizado por Antonio Carlos Diegues no Núcleo de Pesquisas sobre Populações Humanas e Áreas Úmidas Brasileiras da Universidade de São Paulo, o termo sociedades tradicionais refere-se "a grupos humanos culturalmente diferenciados que historicamente reproduzem seu modo de vida, de forma mais ou menos isolada, com base em modos de cooperação social e formas específicas de relações com a natureza, caracterizados tradicionalmente pelo manejo sustentado do meio ambiente" (DIEGUES et al, 2000, p. 22) O estudo ainda apresenta um longo estudo de características destas comunidades, tais como: 
a) dependência frequente, por uma relação de simbiose entre a natureza, os ciclos naturais e os recursos naturais renováveis com os quais se constrói um modo de vida;

b) conhecimento aprofundado da natureza e de seus ciclos, o que se reflete na elaboração de estratégias de uso e de manejo dos recursos naturais. Este conhecimento é transmitido intergeracionalmennte pela oralidade;

c) presença da noção de território ou espaço onde o grupo social se reproduz economicamente e socialmente;

d) ocupação deste território por várias gerações, ainda que alguns membros tenham se deslocado para centros urbanos e voltado para a terra de seus antepassados;

e) importância significativa das atividades de subsistência, ainda que paralelamente a produções de mercadoria;

f) reduzida acumulação de capital;

g) importância reservada à unidade familiar doméstica ou comunal e às relações de parentesco ou compadrio para o exercício de atividades econômicas, sociais e culturais;

h) importância de simbologias, mitos e rituais associados à caça, à pesca e a atividades extrativistas;

i) utilização restrita de instrumentos tecnológicos, com impacto limitado sobre o meio ambiente. Percebe-se, outrossim, reduzida divisão técnica e social do trabalho;

j) reduzido poder político, que em geral é partilhado com grupos de centros urbanos;

k) auto-identificação ou identificação pelos outros de se pertencer a uma cultura distinta das outras (Ibid, p. 21-22).

A problemática da auto-identificação recebe aqui tratamento relevante. Como destaca Frédéric Maguet, ao comentar a Convenção para a Salvaguarda do Patrimônio Cultural imaterial, os agentes do reconhecimento são os próprios interessados, e não mais especialistas e peritos designados numa carga redistributiva de cultura. Desta maneira, os grupos de praticantes de uma cultura no território de um Estado têm a possibilidade de assegurar sua perpetuação como grupo, o que garante um sentimento de identidade e de continuidade. Nesta ótica, existe uma relação de definição circular entre o patrimônio cultural imaterial e as comunidades (MAGUET, 2011, p. 48-49).

A nível normativo, a Convenção 169 da Organização 
Internacional do Trabalho, ratificada pelo Brasil em 2002 através do Decreto Legislativo $n^{\circ} 143$, também contribui para esta delimitação teórica. De acordo com sua redação, são perceptíveis três critérios para determinar os grupos a quem se aplica: (a) a existência de condições sociais, culturais e econômicas diferentes de outros setores da sociedade nacional; (b) a presença de uma organização social regida total ou parcialmente por regras e tradições próprias; e a (c) autodeterminação, entendida como a consciência que o grupo possui de sua própria identidade tribal ${ }^{10}$.

Finalmente, em 2007, a Assembleia Geral da Organização das Nações Unidas aprovou a Declaração sobre os Direitos dos Povos Indígenas. Negociada desde 1993, o texto da declaração foi fruto de 11 anos de negociações no seio de um grupo de trabalho da Comissão de Direitos Humanos. Contudo, antes da aprovação definitiva, a redação foi rejeitada por um conjunto de países. Uma moção proposta pela delegação de Namibie (em nome de uma série de Estados africanos) e defendida por outros países, como os Estados Unidos, Canadá, Austrália, Nova Zelândia e a Rússia, durante a $61^{\circ}$ sessão da Comissão de Direitos Humanos em 2005, demandava o adiamento da adoção da declaração. A redação final somente foi aprovada em 2007, ainda com os votos contrários da Austrália, Canadá, Estados Unidos e Nova Zelândia (DEROCHE, 2008, p. 225) ${ }^{11}$.

Cabe ressaltar que a leitura da versão original da declaração em língua francesa (Déclaration des Nations Unies sur les Droits des Peuples Autochtones) demonstra que o termo autóchtone é traduzido para o português como indígena (e não autóctone). Contudo, no contexto brasileiro o termo indígena normalmente recebe um

${ }^{10}$ INSTITUTO SOCIOAMBIENTAL. Consulta livre, prévia e informada na $\begin{array}{lllll}\text { Convenção } & 169 & \text { da } & \text { OIT. } & \text { Disponível }\end{array}$ www.socioambiental.org/inst/esp/consulta_previa/?q=convencao-169-da-oit-nobrasil. Acesso em 20/08/2015.

${ }^{11} \mathrm{O}$ argumento de violação à soberania foi utilizado por estes países. Segundo o embaixador australiano Robert Hill, por exemplo, "a Austrália expressou sua oposição ao uso do termo 'autodeterminação', que está mais relacionado com situações de descolonização. Não podemos respaldar um texto que põe em perigo a integridade territorial de um país democrático" (disponível em http://g1.globo.com/Noticias/Mundo/0,,MUL104055-5602,00-

ONU+APROVA+DECLARACAO+DOS+DIREITOS+DOS+POVOS+INDIGENA S.html. Acesso em 25/09/2015). 
significado mais restrito, referindo-se apenas aos povos e descendentes que habitavam o território brasileiro quando da chegada dos portugueses em 1500. Em sua utilização cotidiana, a expressão povos indígenas, em que pese tenha sido adotada na versão em língua portuguesa da declaração de 2007, não abrange o conjunto dos povos e comunidades tradicionais do país. Neste sentido, destaca Lucila Pinsard Vianna que a expressão população tradicional diz respeito genericamente e atemporalmente para definir uma vaga categoria populacional, assim como indigenous people, native people, local people, populações autóctones, tradicional societies ou sociedades tribais, sempre com referência a populações étnicas. "Há, portanto, diferenças entre população tradicional, tal como empregado no Brasil, referente às sociedades rústicas, e indigenous people, que se refere a povos tribais, a indígenas ou a nativos originais" (VIANNA, 2008, p. 242-243).

No âmbito nacional, o primeiro esforço governamental para o reconhecimento da noção de comunidades tradicionais é observado em 1992, com a criação pelo IBAMA do Centro Nacional para o Desenvolvimento Sustentado das Populações Tradicionais (CNPT), o qual congregou algumas das organizações representativas destes grupos (CALEGARE, 2014, p. 125). Ainda na introdução da portaria, observa-se uma primeira tentativa de conceituação da expressão populações tradicionais, entendidas como "aquelas que tradicional e culturalmente tem sua subsistência baseada no extrativismo de bens naturais" (BRASIL, 1992, p. 1637).

Um novo conceito é esboçado na redação original da lei 9.985/2000, a qual instituiu o Sistema Nacional de Unidades de Conservação. De acordo com a então redação do artigo $2^{\circ}, \mathrm{XV}$, que restou vetado, populações tradicionais são

os grupos humanos culturalmente diferenciados, vivendo há, no mínimo, três gerações em um determinado ecossistema, historicamente reproduzindo seu modo de vida, em estreita dependência do meio natural para sua subsistência e utilizando os recursos naturais de forma sustentável.

$\mathrm{O}$ veto ao artigo, sugerido pelo Ministério do Meio Ambiente, partia da alegação de que o dispositivo mostrava-se de tal modo 
vasto que seria possível incluir, com um esforço de imaginação, toda a população do Brasil (BRASIL, 2000). Saliente-se que o veto foi defendido também por algumas comunidades extrativistas, as quais não atendiam o requisito de habitar nas terras há, no mínimo, três gerações (SANTILLI, 2005, p. 127). Deste modo, a redação final da lei sancionada repetiu em dezesseis ocasiões a expressão comunidades tradicionais sem, contudo, precisar qual é o seu conteúdo conceitual.

A noção precisa de povos e comunidades tradicionais (PCTs) é adotada finalmente pelo Decreto 6.040, de 07 de fevereiro de 2007, cujo teor instituiu a Política Nacional de Desenvolvimento Sustentável das Comunidades Tradicionais - PNPCT. Nos termos do decreto, tratam-se de

grupos culturalmente diferenciados e que se reconhecem como tais, que possuem formas próprias de organização social que ocupam e usam territórios e recursos naturais como condição para sua reprodução cultural, social, religiosa, ancestral e econômica, utilizando conhecimentos, inovações e práticas gerados e transmitidos pela tradição $\left(\operatorname{art.} 3^{\circ}, \mathrm{I}\right)$.

Saliente-se que a lei 13.123/2015, cujo teor instituiu o marco legal da biodiversidade, repetiu o mesmo conceito, em seu artigo $2^{\circ}$, IV. Com sentido semelhante ao apresentado pelo decreto observamse os apontamentos elaborados por Juliana Santilli. A autora destaca que "a própria formulação do conceito de populações tradicionais está associada a um novo modelo de conservação (socioambiental), cujo núcleo central considera a enorme diversidade cultural existente no Brasil, e as formas culturalmente diferenciadas de apropriação e utilização dos recursos naturais" (SANTILLI, 2005, p. 129).

Embora a categoria surja a partir de grupos específicos, notadamente aqueles preocupados com a continuidade de suas atividades econômicas extrativistas, é evidente que o conceito abarca um universo mais amplo de populações. Nesta linha podem ser inclusos não apenas os povos indígenas, mas também os ribeirinhos, os caboclos, os pescadores artesanais, os pomeranos, seringueiros, castanheiros, faxinalenses, panteneiros, etc. Nessa linha, observa-se o teor do decreto 8.750/2016, que instituiu o Conselho Nacional dos 
Povos e Comunidades Tradicionais. Em que pese o decreto não repita ou inaugure qualquer conceito, ele apresenta um rol de comunidades que possuem assento no conselho. O referido rol incluiu os seguintes grupos: povos indígenas; comunidades quilombolas; povos e comunidades de terreiro/povos e comunidades de matriz africana; povos ciganos; pescadores artesanais; extrativistas; extrativistas costeiros e marinhos; caiçaras; faxinalenses; benzedeiros; ilhéus; raizeiros; geraizeiros; caatingueiros; vazanteiros; veredeiros; apanhadores de flores sempre vivas; pantaneiros; morroquianos; povo pomerano; catadores de mangaba; quebradeiras de coco babaçu; retireiros do Araguaia; comunidades de fundos e fechos de pasto; ribeirinhos; cipozeiros; andirobeiros e caboclos. $\mathrm{O}$ rol trazido pelo decreto não esgota $\mathrm{o}$ universo dos povos e comunidades tradicionais, em que pese seja o texto mais extenso verificado na legislação brasileiro.

Finalmente, como pondera novamente Julliana Santilli, a própria categoria de agricultores familiares (vistos na sua concepção standard) pode ser inclusa na noção de comunidades tradicionais:

não podemos deixar de mencionar que estes - ainda que não expressamente reconhecidos pelo ordenamento jurídico como tais ${ }^{12}-$ certamente se encaixam dentro do conceito de "populações tradicionais", ou de "comunidades locais", conforme a opção terminológica que se adote. Os agricultores tradicionais, ou familiares, são, em grande parte, responsáveis pela manutenção da diversidade de espécies e variedades agrícolas. Adotam mecanismos de seleção e melhoramento genético, domesticação e intercâmbio de sementes que asseguram a variabilidade genética das plantas cultivadas e a conservação da agrobiodiversidade. Portanto, as políticas de conservação in situ da diversidade biológica agrícola não podem deixar de reconhecer e valorizar o papel dos agricultores no manejo da diversidade fitogenética, e de promover as suas práticas e sistemas agrícolas tradicionais (SANTILLI, 2005, p. 130).

Em suma, não há uma fronteira rígida entre as duas categorias identificadas neste trabalho. Determinadas comunidades podem, em

${ }^{12}$ Saliente-se que a obra mencionada foi publicada no ano de 2005 , anteriormente, portanto, ao Decreto 6.040 de 2006. 
certas ocasiões, se enquadrar em ambos os grupos de agricultura familiar, sendo identificados, portanto, tanto por seus aspectos socioeconômicos, como histórico-culturais.

\section{CONCLUSÃO}

Embora outras ciências, notadamente a sociologia, já formulassem conceitos em torno da noção de agricultura familiar, no âmbito jurídico brasileiro um conceito preciso apenas foi positivado em 2006, com a edição dei 11.326. A lei apresentou um conceito socioeconômico de agricultura familiar, observados em seu artigo $3^{\circ}$. Contudo, a lei ainda incluiu entre os beneficiários da lei, um conjunto de grupos identificados a partir de elementos culturais, utilizando-se de uma expressão ampla, qual seja, povos e comunidades tradicionais.

O presente artigo apresentou como hipótese a idéia de que a lei estabeleceu dois grupos distintos de agricultores familiares (que algumas ocasiões podem se convergir): um deles identificados a partir de elementos socioeconômicos (limite do tamanho da propriedade, natureza da mão de obra utilizada, limite da renda familiar e forma de gestão), e outro grupo identificado a partir de elementos culturais.

Para uma precisão conceitual de ambos os grupos, torna-se necessário a importação de noções advindas de outras normas. Exemplificadamente, a definição de módulo fiscal é localizada no estatuto da Terra, enquanto que os limites de renda da agricultura familiar são vislumbrados nos regramentos do Conselho Monetário Nacional que norteiam o crédito agrícola. A legislação brasileira definidora da idéia de povos e comunidades e tradicionais não adotou uma metodologia enumerativa, mas apresentou um rol de requisitos que possibilita a inclusão irrestrita de todos os grupos que (a) se reconheçam como tradicionais, (b) possuam formas próprias de organização social, (c) ocupem e usem seus territórios e recursos naturais para a reprodução cultural, social, religiosa, ancestral e econômica, (d) e utilizem conhecimentos, inovações e práticas transmitidos pela tradição.

A adoção de um conceito amplo de agricultura familiar pela legislação brasileira apresentou um evidente objetivo de propiciar a 
elaboração de políticas públicas que possibilitem o combate ao déficit de justiça social tanto do ponto de vista da distribuição, como do reconhecimento cultural. Tais políticas, contudo, ainda carecem de maior atenção do poder público federal, o qual continua e reservar parte insignificante de seu orçamento para o fortalecimento das categoria estudadas neste artigo.

\section{REFERÊNCIAS BIBLIOGRÁFICAS}

ARAUJO JUNIOR, Ari Francisco de; SHIKIDA, Claudio; ALVARENGA, Patrícia Silva. Economia política da disputa por terras em Minas Gerais. Revista de Economia e Sociologia Rural, Brasília , v. 46, n. 3, set. 2008.

ARAÚJO, Ana Valéria. Povos Indígenas e a Lei dos Brancos: o direito à diferença. Brasília: Ministério da Educação; Museu Nacional/LACED, 2006.

BRASIL. DIÁRIO OFICIAL DA UNIÃO. Edição de 11 de fevereiro de 1992.

BRASIL. PRESIDÊNCIA DA REPÚBLICA, Mensagem n ${ }^{\circ}$ 967, de 18 de julho de 2000. Disponível em http://www.planalto.gov.br/ccivil_03/Leis/Mensagem_Veto/2000/Mv096700.htm. Acesso em 25/09/2015.

CALEGARE, Marcelo Gustavo Aguilar; HIGUCHI, Maria Inês Gasparetto; BRUNO, Ana Carla dos Santos. Povos e Comunidades Tradicionais: das Áreas Protegidas à visibilidade política de grupos sociais portadores de identidade étnica e coletiva. Ambiente \& Sociedade. São Paulo, v. XVII, $\mathrm{n}^{\circ} 3$, jul./set. 2014.

CUNHA, Manuela Carneiro da; ALMEIDA, Mauro W. B. Quem são as populações tradicionais? Disponível em www.uc.socioambiental.org/territórios-de-ocupação/quem-são-aspopulações-tradicionais. Acesso em 02/09/2015.

DEROCHE, Fréderic. Les peuples autochtones et leur relation originale à la terre. Un questionnement pour l'ordre mondial. Paris: L'Harmattan, 2008.

DIEGUES, Antonio Carlos; ARRUDA, Rinaldo Sergio Vieira; SILVA, Viviane Capezzuto Ferreira da; FIGOLS, Francisca Aida Barboza; ANDRADE, Daniela. Os Saberes Tradicionais e a Biodiversidade no Brasil. São Paulo: MMA, COBIO, NUPAUB/USP, 2010. 
EMPRESA BRASILEIRA DE PESQUISA AGROPECUÁRIA. Documento 146. Variação Geográfica do Tamanho dos Módulos Fiscais no Brasil. Elena Charlotte Landau et al. Sete Lagoas: Embrapa Milho e Sorgo, 2012, p. 18. Disponível em http://aiba.org.br/wpcontent/uploads/2013/11/variacao-Geografica-do-Tamanho-dos-ModulosFiscais-no-Brasil-Embrapa.pdf. Acesso em 15/12/2015.

INSTITUTO SOCIOAMBIENTAL. Consulta livre, prévia e informada na Convenção 169 da OIT. Disponível em www.socioambiental.org/inst/esp/consulta_previa/?q=convencao-169-daoit-no-brasil. Acesso em 20/08/2015.

LANDAU, Elena Charlotte; CRUZ, Roberta Kelly da; HIRSCH, André; PIMENTA, Fernando Martins; GUIMARÃES, Daniel Pereira. Variação geográfica do tamanho dos módulos fiscais no Brasil. Documentos 146. Sete Lagoas: Embrapa Milho e Sorgo, 2012.

MAGUET, Frédéric. L'image des communautés dans l'espace public. In: Le Patrimoine Culturel Immatériel. Enjeux d'une nouvelle catégorie (coordonné par por Chiara Bortolotto). Paris: Éditions de la Maison des Sciences de l'Homme, 2011.

MONTANARI JUNIOR, Isaias. Demarcação de Terras Indígenas e cooperação internacional. Análise do PPTAL - Programa Piloto de Proteção das Terras Indígenas na Amazônnia Legal. Curitiba: Juruá, 2013.

SANTILLI, Juliana. Socioambientalismo e Novos Direitos. São Paulo: Fundação Peirópolis, 2005.

SCHNEIDER, Sergio. Teoria Social, Agricultura Familiar e Pluriatividade. Revista Brasileira de Ciências Sociais. Vol. 18, nº 51, fev. 2003.

SCHNEIDER, Sergio. Agricultura familiar e desenvolvimento rural endógeno: elementos teóricos e um estudo de caso. In. Froehlich, J.M; Vivien Diesel (org.). Desenvolvimento Rural - Tendências e debates. Ijuí: Unijuí, 2006.

VIANNA, Lucila Pinsard. De Invisíveis a protegonistas. Populações Tradicionais e Unidades de Conservação. São Paulo. Annablume; FAPESP, 2008. 
EDITORA E GRÁFICA DA FURG CAMPUS CARREIROS

CEP 96203900

editora@furg.br 